\title{
Optimalisasi Penggunaan Variasi Filter Pada Pesawat Sinar-X Mobile Guna Mencapai Nilai Entrance Skin Exposure (Ese) Sesuai Organ Pemeriksaan
}

\author{
Oki Dewi Pamungkas ${ }^{1}$, Utari $^{2}$, Suharyana ${ }^{3}$, Riyatun ${ }^{4}$, Nining Hargiani ${ }^{5}$ \\ 1,2,3,4 Program Studi S1 Fisika, Universitas Sebelas Maret, Jl. Ir. Sutami No. 36 Kentingan, Surakarta \\ ${ }^{5}$ Loka Pengamanan Fasilitas Kesehatan; Komplek RC., Jl. Kolonel Sutarto, Jebres, Kec. Jebres, Kota \\ Surakarta 57126
}

Email : oki_depa@student.uns.ac.id

\begin{abstract}
This study was to determine the effect of variations in the type and thickness of the filter on the ESE and HVL values. The use of filters aims to eliminate low energy X-rays, increase effective energy, and reduce dose acceptance to patients. This variation of Al with Cu and Al with Zn filters uses a voltage (70, 80, and 90) $\mathrm{kV}, 20 \mathrm{mAs}, 100 \mathrm{~cm} \mathrm{SSD}$, and an irradiation field area of $10 \mathrm{~cm} \times 10 \mathrm{~cm}$. The result of measuring the consistency of the X-ray tube voltage has the largest error value of $4.93 \%$. At a voltage of $90 \mathrm{kV}$, the measurement results of the variation of Al filter with $\mathrm{Cu}$ thickness of $0.2 \mathrm{~mm}$ and $0.3 \mathrm{~mm}$ and Al filter with Zn thickness of $0.25 \mathrm{~mm}$ and $0.50 \mathrm{~mm}$ are within the tolerance limits of the thorax examination organ. While the measurement results of the Al filter variants with a $\mathrm{Cu}$ thickness of $0.4 \mathrm{~mm}$ and an Al filter with a Zn thickness of $0.75 \mathrm{~mm}$ are within the tolerance limit of the cranium examination organ. The ESE half value can use $3.03 \mathrm{~mm} \mathrm{Al}$, equivalent to $0.135 \mathrm{~mm} \mathrm{Cu}$ or $0.22 \mathrm{~mm} \mathrm{Zn}$.
\end{abstract}

Keywords: Filters, X-rays, ESE, HVL, voltage

\begin{abstract}
Abstrak: Penelitian ini untuk mengetahui pengaruh variasi jenis dan ketebalan filter terhadap nilai ESE dan HVL. Penggunaan filter bertujuan untuk mengeliminasi sinar-X energi rendah, meningkatkan energi efektif, dan mengurangi penerimaan dosis pada pasien. Variasi filter $\mathrm{Al}$ dengan $\mathrm{Cu}$ dan $\mathrm{Al}$ dengan $\mathrm{Zn}$ ini menggunakan tegangan $(70,80$, dan 90$) \mathrm{kV}, 20 \mathrm{mAs}$, SSD $100 \mathrm{~cm}$, dan luas lapangan penyinaran 10 $\mathrm{cm} \times 10 \mathrm{~cm}$. Hasil pengukuran konsistensi tegangan tabung sinar-X memiliki nilai error terbesar 4,93\%. Pada tegangan $90 \mathrm{kV}$ hasil pengukuran variasi filter $\mathrm{Al}$ dengan $\mathrm{Cu}$ ketebalan $0,2 \mathrm{~mm}$ dan 0,3 $\mathrm{mm}$ dan filter Al dengan $\mathrm{Zn}$ ketebalan 0,25 $\mathrm{mm}$ dan $0,50 \mathrm{~mm}$ dalam batas toleransi organ pemeriksaan thorax. Sedangkan hasil pengukuran varisi filter $\mathrm{Al}$ dengan $\mathrm{Cu}$ ketebalan $0,4 \mathrm{~mm}$ dan filter $\mathrm{Al}$ dengan $\mathrm{Zn}$ ketebalan $0,75 \mathrm{~mm}$ dalam batas toleransi organ pemeriksaan cranium. Nilai setengah ESE dapat menggunakan 3,03 $\mathrm{mm} \mathrm{Al}$, setara dengan $0,135 \mathrm{~mm} \mathrm{Cu}$ atau 0,22 $\mathrm{mm} \mathrm{Zn}$.
\end{abstract}

Kata kunci: Filter, sinar-X, ESE, HVL, tegangan

\section{PENDAHULUAN}

Pemeriksaan radiologi merupakan pemeriksaan dengan menggunakan teknologi pencitraan untuk mendiagnosa suatu penyakit. Pemeriksaan radiologi ini memanfaatkan radiasi pengion yaitu sinar-X. Ketika radiasi sinar-X menembus bahan atau materi, maka sinar-X akan berinteraksi dengan atom dan menghasilkan ionisasi (Hiswara, 2015).

Sinar-X memiliki energi yang bergantung dari tegangan pemercepat elektron yang dipasang antara anoda dan katoda. Tegangan tersebut yang akan mempengaruhi energi dan daya tembus sinar-X. Daya tembus akan semakin besar apabila tegangan kerjanya juga besar. Berkas sinar$\mathrm{X}$ medis memiliki spektrum kontinu, artinya pada berkas mengandung sinar- $\mathrm{X}$ energi tinggi dan energi rendah. Efek dari sinar-X energi rendah pada obyek organ dapat berupa deterministik atau stokastik (Leong et al., 2016). 
Penggunaan Half Value Layer (HVL) atau nilai tebal paruh untuk menyatakan ukuran kualitas sinar-X. HVL merupakan ketebalan bahan penyerap untuk menguangi besarnya intensitasi sinar-X menjadi setengah dari intensitas semula. Semakin tinggi nilai HVL maka daya tembus sinar-X juga semakin tinggi, dan sebaliknya. Jika radiasi dengan intensitas mulamula $\left(\mathrm{I}_{0}\right)$ melewati bahan dengan ketebalan $(\mathrm{x})$ dan koefisien serapan $(\mu)$, maka intesitas yang lolos (I) :

$$
I=I_{0} e^{-\mu x}
$$

Kemudian apabila intensitas radiasi setelah melewati bahan tinggal setengah dari intensitas mula-mula, maka tebal bahan tersebut adalah HVL :

$$
\mu=\frac{0,693}{\mathrm{HVL}}
$$

Untuk mengurangi intensitas radiasi menjadi setengah dari intensitas semula atau HVL maka membutuhkan suatu bahan yaitu filter. Filter yang optimal adalah yang dapat menyerap energi sinar- $X$ rendah sehingga hanya sinar- $X$ dengan energi tinggi yang lolos. Dengan demikian pasien juga akan menerima dosis serendah mungkin (Azam et al., 2017).

Dosis pasien pada pemeriksaan radiodiagnostik secara umum ada 3 cara, yaitu paparan pada permukaan kulit atau Entrance Skin Exposure (ESE), paparan pada organ reproduktif atau the gonodal dose, dan dosis pada sumsum tulang atau a mean marrow dose. ESE merupakan paparan pada pusat sumbu sinar-X dimana titik tersebut adalah daerah yang akan terkena radiasi (Dhahryan \& Much., 2009).

Tabel 1. Nilai ESE pada Organ Pemeriksaan (Sprawls,1995)

\begin{tabular}{cc}
\hline Pemeriksaan & ESE (mGy) \\
\hline Cranium & $0,348-0,522$ \\
Thorax $(P A)$ & $0,087-0,26$ \\
Thorax (Lateral) & $0,435-0,87$ \\
Abdomen & $0,87-3,5$ \\
Columna vertebralis (Lateral) & $4,35-13,04$ \\
Pelvis & $2,17-4,35$ \\
\hline
\end{tabular}

\section{METODE PENELITIAN}

Alat yang digunakan dalam penelitian ini adalah pesawat sinar-X mobile Toshiba, detektor Piranha dengan Detector (s): MPD S / N MP2-15040488 dan Meter (s): Piranha S / N CB215040486 , waterpass, survey meter, dan laptop yang terinstal software ocean. Sedangkan bahan yang digunakan yaitu variasi jenis dan ketebalan filter, dimana $\mathrm{Al}$ merupakan filter bawaan dari pesawat sinar-X mobile dan filter tambahan yaitu filter $\mathrm{Cu}(0,2 ; 0,3 ;$ dan 0,4$) \mathrm{mm}$ dan $\mathrm{Zn}(0,25$; $0,50$; dan 0,75$) \mathrm{mm}$. Variasi tegangan yang digunakan $(70,80$, dan 90) $\mathrm{kV}, 20 \mathrm{mAs}$, SSD 100 $\mathrm{cm}$, dan luas lapangan penyinaran $10 \mathrm{~cm}$ x $10 \mathrm{~cm}$. Dari data set kemudian didapatkan nilai ESE dan HVL yang kemudian dibuat grafik hubungan yaitu grafik hubungan tegangan terhadap ESE, ketebalan terhadap ESE, dan tegangan terhadap HVL. Kemudian ditentukan nilai HVL untuk masing-masing filter yang digunakan tersebut dengan menggunakan persamaan (1) dan (2). 


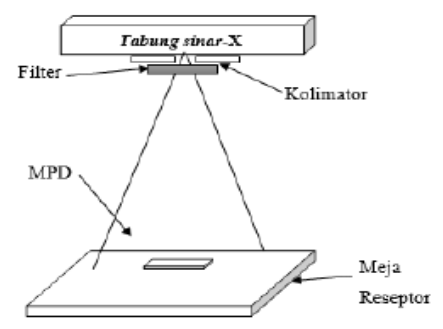

Gambar 1. Pengukuran ESE dan HVL (Litasova dkk., 2018)

\section{HASIL DAN PEMBAHASAN}

Tabel 2. Nilai Error untuk Tegangan Tabung tanpa Filter

\begin{tabular}{cc}
\hline Tegangan $(\mathrm{kV})$ & Error $(\%)$ \\
\hline 70 & 4,93 \\
80 & 4,67 \\
90 & 3,93 \\
\hline
\end{tabular}

Penelitian pertama yaitu penentuan konsistensi tegangan tabung tanpa filter dari pesawat sinar-X mobile. Penelitian sesuai data set dan variasi tegangan $(70,80$, dan 90) $\mathrm{kV}$. Berdasarkan nilai error pada tabel 2. maka pesawat sinar-X mobile masih di bawah batas toleransi yaitu $\pm 10 \%$. Berdasarkan hal tersebut maka dapat berkesimpulan bahwa kinerja pesawat sinar-X mobile masih dalam keadaan baik.

Penelitian selanjutnya yaitu dengan penggunaan variasi jenis dan ketebalan filter. Nilai dari masing-masing jenis filter tersebut selanjutnya untuk membuat grafik hubungan. Grafik hubungan yang pertama yaitu tegangan terhadap ESE. Variabel bebas atau sumbu x adalah nilai tegangan dan variabel terikat atau sumbu y adalah nilai ESE.
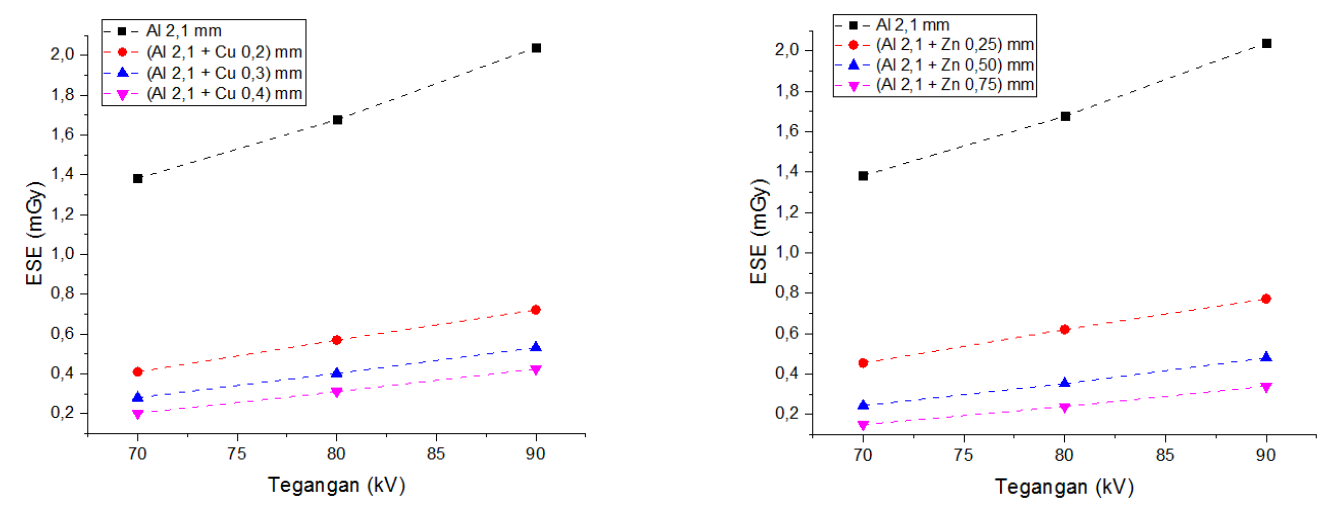

Gambar 2. Grafik Hubungan Tegangan terhadap ESE a) Al dan Cu b) Al dan Zn

Berdasarkan gambar 2. a) dan b) maka terlihat bahwa untuk filter $\mathrm{Al}$ dan $\mathrm{Cu}$ maupun $\mathrm{Al}$ dan Zn sama, semakin besar nilai tegangan tabung maka semakin besar pula nilai ESE. Besarnya nilai ESE meningkat sebanding dengan kenaikan tegangan tabung sinar-X. Hal ini terjadi karena besarnya intensitas sinar-X berbanding lurus dengan kuadrat tegangan tabung. Dengan demikian, setiap kenaikan nilai tegangan tabung dengan arus waktu konstan, hal ini akan meningkatkan nilai intensitas radiasi, dan kenaikan intensitas radiasi akan berdampak pada kenaikan ESE. 
Dari kedua gambar tersebut juga terlihat bahwa variasi filter Al dan $\mathrm{Zn}$ menghasilkan nilai ESE paling besar yaitu $0,772 \mathrm{mGy}$. Nilai tersebut pada tegangan terbesar $90 \mathrm{kV}$ dan ketebalan terkecil 0,25 mm. Hal ini dikarenakan bahan Al dan Zn menyerap berkas sinar-X tidak sebanyak filter dengan bahan $\mathrm{Al}$ dan $\mathrm{Cu}$. Al dan $\mathrm{Zn}$ juga memiliki massa jenis terkecil daripada $\mathrm{Cu}$ yaitu massa jenis $\mathrm{Al}$ sebesar $2,7 \mathrm{~g} / \mathrm{cm}^{3}$ dan $\mathrm{Zn} 7,13 \mathrm{~g} / \mathrm{cm}^{3}$ sementara $\mathrm{Cu} 8,96 \mathrm{~g} / \mathrm{cm}^{3}$.
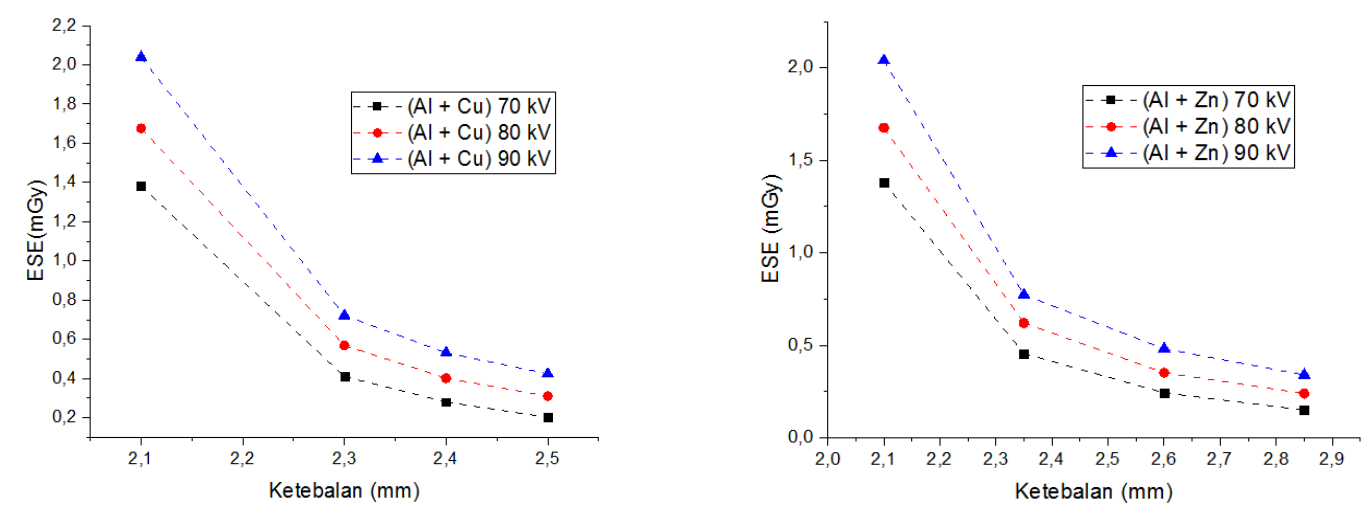

Gambar 3. Grafik Hubungan Ketebalan terhadap ESE a) Al dan $\mathrm{Cu}$ b) $\mathrm{Al}$ dan $\mathrm{Zn}$

Gambar 3. a) dan b) memperlihatkan bahwa semakin tebal filter maka penyerapan berkas sinar-X semakin besar, sehingga nilai ESE akan semakin menurun. Penyerapan ESE dengan kombinasi filter $\mathrm{Al}$ dengan $\mathrm{Zn}$ ialah paling sedikit daripada dengan filter $\mathrm{Al}$ dengan $\mathrm{Cu}$, hal ini karena massa jenis Al yaitu $2,7 \mathrm{~g} / \mathrm{cm}^{3}$ dan $\mathrm{Zn} 7,13 \mathrm{~g} / \mathrm{cm}^{3}$ sementara $\mathrm{Cu} 8,96 \mathrm{~g} / \mathrm{cm}^{3}$.

Berdasarkan referensi dari (Sprawls, 1995) maka dari data hasil penelitian dipilih salah satu tegangan yaitu $90 \mathrm{kV}$. Dari tegangan tersebut terlihat bahwa penggunaan variasi filter $\mathrm{Al}$ dengan $\mathrm{Cu}$ ketebalan 0,2 $\mathrm{mm}$ dan 0,3 mm dan filter $\mathrm{Al}$ dengan $\mathrm{Zn}$ ketebalan 0,25 mm dan 0,50 $\mathrm{mm}$ dalam batas toleransi untuk organ pemeriksaan thorax yaitu $(0,087-0,87) \mathrm{mGy}$. Sedangkan varisi filter $\mathrm{Al}$ dengan $\mathrm{Cu}$ ketebalan 0,4 $\mathrm{mm}$ dan filter $\mathrm{Al}$ dengan $\mathrm{Zn}$ ketebalan 0,75 $\mathrm{mm}$ dalam batas toleransi untuk organ pemeriksaan cranium $(0,348-0,522) \mathrm{mGy}$.
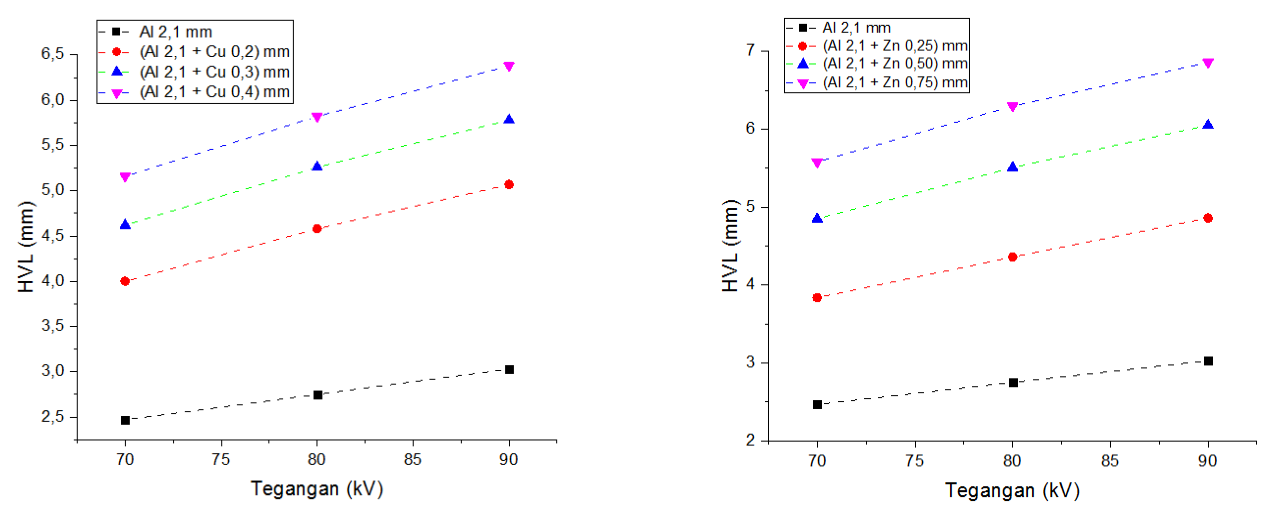

Gambar 4. Grafik Hubungan Tegangan terhadap HVL a) Al dan Cu b) Al dan Zn

Berdasarkan gambar 4. a) dan b) maka terlihat hubungan tegangan terhadap nilai HVL. Nilai paruh akan semakin besar jika tegangan tabung sinar-X semakin besar faktor eksposinya, sehingga membutuhkan ketebalan filter yang semakin besar pula. Massa jenis pada bahan sebagai kombinasi filter mempengaruhi penyerapan sinar-X. Semakin besar massa jenis bahan maka semakin besar penyerapan sinar-X. Oleh karena itu memerlukan ketebalan bahan yang lebih sedikit pada massa jenis yang lebih besar. 
Dari kedua gambar grafik hubungan tersebut juga tampak bahwa kenaikan tegangan mengakibatkan kenaikan nilai HVL terukur. Hal ini dikarenakan kenaikan tegangan tabung akan mempercepat elektron yang menumbuk target, sehingga sinar-X yang diproduksi memiliki energi yang lebih tinggi. Energi sinar-X yang lebih tinggi menyebabkan daya tembusnya juga mengalami kenaikan. Sehingga nilai HVL juga mengalami kenaikan. Tampak dari grafik bahwa kenaikan nilai HVL relatif linear.

Tabel 3. Nilai HVL Al, Cu, dan $\mathrm{Zn}$

\begin{tabular}{ccccc}
\hline $\begin{array}{c}\text { Tegangan } \\
(\mathrm{kV})\end{array}$ & $\begin{array}{c}\text { Nilai Paruh ESE } \\
(\mathrm{mGy})\end{array}$ & $\begin{array}{c}\text { HVL Al } \\
(\mathrm{mm})\end{array}$ & $\begin{array}{c}\text { HVL Cu } \\
(\mathrm{mm})\end{array}$ & $\begin{array}{c}\text { HVL Zn } \\
(\mathrm{mm})\end{array}$ \\
\hline 70 & 0,69 & $2,47 \pm 0,28$ & $0,20 \pm 0,04$ & $0,33 \pm 0,05$ \\
80 & 0,84 & $2,75 \pm 0,28$ & $0,24 \pm 0,04$ & $0,39 \pm 0,05$ \\
90 & 1,02 & $3,03 \pm 0,28$ & $0,27 \pm 0,04$ & $0,44 \pm 0,05$ \\
\hline
\end{tabular}

Sebagaimana terlihat pada Tabel 3. nilai HVL untuk masing-masing filter yaitu $\mathrm{Al}, \mathrm{Cu}$, dan Zn. Berdasarkan Tabel 2. terlihat bahwa peningkatan faktor paparan tegangan tabung sinar-X akan menyebabkan peningkatan nilai setengah ESE. Untuk mencapai nilai setengah ESE pada tegangan tabung $90 \mathrm{kV}$ membutuhkan filter Al sebesar 3,03 $\pm 0,28 \mathrm{~mm}$. Nilai tersebut akan

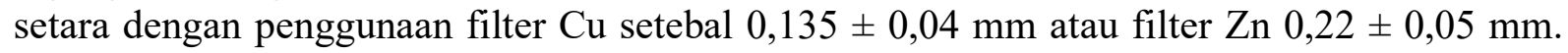
Kepadatan bahan filter berpengaruh pada penyerapan intensitas sinar-X dimana intensitas yang diserap filter $\mathrm{Cu}$ adalah yang terbesar daripada dengan kedua filter yang lainnya. Sehingga akan terjadi penyerapan sinar-X lebih banyak jika menggunakan filter $\mathrm{Cu}$ dengan ketebalan $0,135 \pm$ $0,04 \mathrm{~mm}$ dan penggunaan filter $\mathrm{Zn}$ dengan tebal 0,22 $\pm 0,05 \mathrm{~mm}$ untuk penyerapan yang lebih sedikit.

\section{KESIMPULAN}

Penggunaan variasi filter $\mathrm{Cu}$ ketebalan $0,2 \mathrm{~mm}$ dan $0,3 \mathrm{~mm}$ serta filter Zn ketebalan 0,25 $\mathrm{mm}$ dan $0,50 \mathrm{~mm}$ dalam batas toleransi untuk pemeriksaan organ thorax $(0,087-0,87) \mathrm{mGy}$. Sedangkan varisi filter $\mathrm{Cu}$ ketebalan $0,4 \mathrm{~mm}$ dan filter $\mathrm{Zn}$ ketebalan 0,75 $\mathrm{mm}$ dalam batas toleransi untuk pemeriksaan organ cranium $(0,348-0,522) \mathrm{mGy}$. Setengah nilai ESE pada tegangan $90 \mathrm{kV}$ dapat diperoleh menggunakan filter 3,03 $\pm 0,28 \mathrm{~mm}$ Al. Nilai tersebut juga setara dengan menggunakan filter $0,135 \pm 0,04 \mathrm{~mm} \mathrm{Cu}$ atau 0,22 $\pm 0,05 \mathrm{~mm} \mathrm{Zn}$.

\section{SARAN}

Penelitian dengan variasi jenis filter lebih baik menggunakan bahan yang memiliki kepadatan yang tidak jauh berbeda. Bahan $\mathrm{Cu}$ dan $\mathrm{Zn}$ dapat berguna sebagai bahan filter alternatif selain filter Al pada pesawat sinar-X.

\section{DAFTAR PUSTAKA}

Azam, M., Evi, S., \& Fenia. (2017). Measurement of Entrance Skin Exposure (ESE) Value with Various Types of Filter Materials on Mobile X-Ray Machine Using Exposure Factor of Chest. International Journal of Innovative Research in Advanced Engineering (IJIRAE), 4, 33-36.

Dhahryan., \& Much, A. (2009). Pengaruh Teknik Tegangan Tinggi Terhadap Entrance Skin Exposure (ESE) dan Laju Paparan Radiasi Hambur Pada Pemeriksaan Abdomen. Berkala Fisika, 12(1), 21-26.

Hiswara, E. (2015). Buku Pintar Proteksi dan Keselamatan Radiasi di Rumah Sakit. Jakarta 


\section{Selatan : BATAN Press.}

Leong, D. L., Louise, R.,Wei, Z., \& Patrick, C. B. (2016). IEC 61267 : Feasibility of Type 1100 Aluminium and A Copper/Aluminium Combination for RQA Beam Qualities. Physica Medica, 32, 141-149.

Litasova, S., Eko, H., \& Muchamad, A. (2018). Pengaruh Ketebalan dan Kombinasi Jenis Filter terhadap Nilai Entrance Skin Exposure (ESE) menggunakan Faktor Eksposi Pemeriksaan Kepala.Youngster Physics Journal,7(2),67-75.

Yunitasari, H. D., Evi,S., \& Choirul, A. (2014). Evaluasi Metode Penentuan Half Value Layer (HVL) Menggunakan Multi Purpose Detectore (MPD) Baracuda pada Pesawat SinarX Mobile. Youngster Physics Journal, 3(2), 113-118. 